\title{
Heat transfer over a nonlinearly stretching sheet with non-uniform heat source and variable wall temperature
}

\author{
Mahantesh M. Nandeppanavar ${ }^{1}$, K. Vajravelu ${ }^{2}$, M. Subhas $\mathrm{Abel}^{3}$ and Chiu-On Ng ${ }^{4, *}$ \\ ${ }^{1}$ Department of PG and UG studies in Mathematics, Government College, Gulbarga- \\ 585105 Karnataka, India \\ ${ }^{2}$ Department of Mathematics, University of Central Florida, Orlando, FL 32816, U.S.A. \\ ${ }^{3}$ Department of Mathematics, Gulbarga University, Gulbarga-585106, Karnataka, India \\ ${ }^{4}$ Department of Mechanical Engineering, The University of Hong Kong, Pokfulam Road, \\ Hong Kong
}

\begin{abstract}
In this paper we study the flow and heat transfer characteristics of a viscous fluid over a nonlinearly stretching sheet in the presence of non-uniform heat source and variable wall temperature. A similarity transformation is used to transform the governing partial differential equations to a system of nonlinear ordinary differential equations. An efficient numerical shooting technique with a fourth-order Runge-Kutta scheme is used to obtain the solution of the boundary value problem. The effects of various parameters (such as the power law index $n$, the Prandtl number Pr, the wall temperature parameter $\lambda$, the space dependent heat source parameter $A^{*}$ and the temperature dependent heat source parameter $B^{*}$ ) on the heat transfer characteristics are analyzed. The numerical results for the heat transfer coefficient (the Nusselt number) are presented for several sets of values of the parameters and are discussed. The results reveal many interesting behaviors that warrant further study on the effects of non-uniform heat source and the variable wall temperature on the heat transfer phenomena at the nonlinear stretching sheet.
\end{abstract}

Keywords: Non-uniform heat source, variable wall temperature, nonlinear stretching, heat transfer, skin friction.

\footnotetext{
* Corresponding author. Tel.: (852) 2859 2622; fax: (852) 2858 5415; e-mail address: cong@hku.hk (Chiu-On Ng).
} 


\section{Introduction}

The viscous flow over a stretching sheet has important industrial applications. For example, in metallurgical processes, such as drawing of continuous filaments through quiescent fluids, annealing and tinning of copper wires, glass blowing, manufacturing of plastic and rubber sheets, crystal growing, continuous cooling and fibers spinning, the sheets are stretched continuously. During the manufacture of these sheets, the melt issues from a slit and is subsequently stretched to achieve the desired thickness. The final product with desired characteristics strictly depends upon the stretching rate, the rate of cooling in the process, and the process of stretching. In view of these applications, Sakiadis [1,2] studied the boundary layer flow over a stretched surface. He employed a similarity transformation and obtained a numerical solution for the problem.

Later, Erickson et al. [3] extended the work of Sakiadis [2] to account for mass transfer at the stretched surface. The two dimensional boundary layer flow caused by a linear stretching sheet in an otherwise quiescent fluid was first discussed by Crane [4]. He obtained a closed form exponential solution. Singh [5] studied the effect of non-uniform heat source on hydromagnetic convective flow of a viscoelastic fluid. Grubka and Bobba [6] studied the heat transfer characteristics of a continuous stretching surface with variable temperature. Abel and Nandeppanavar [7-9] studied the effect of non-uniform heat source on viscoelastic boundary layer flows. Further, Abel et al. [10] investigated the effects of viscous dissipation and non-uniform heat source. Abel and Mahesha [11] studied the effects of non-uniform heat source with variable thermal conductivity. Ali [12] investigated the effects of power law index on heat transfer characteristics of a power law fluid flow. Tsai et al. [13] investigated the effects of non-uniform heat source on unsteady stretching sheet.

However, all these studies are restricted to linear stretching of the sheet. It is worth mentioning that the stretching is not necessarily linear. In view of this, Kumaran and Ramanaih [14] studied flow over a quadratic stretching sheet. Magyari and Keller [15], Elbashbeshy [16], Khan and Sanjayanand [17], Sanjayanand and Khan [18], Sajid and Hayat [19], Partha et al. [20] studied the heat transfer characteristics of viscous and 
viscoelastic fluid flows over an exponentially stretching sheet. Vajravelu [21], Vajravelu and Cannon [22], and Cortell [23-25] studied the effects of various parameters governing the flow of a viscous fluid over a nonlinearly stretching sheet. In all these studies with nonlinear stretching sheet, the authors ignored the effects of the heat source, which is very important in exothermic and endothermic processes.

The analysis of the temperature field as modified by the generation or absorption of heat in moving fluids is important in view of several physical problems, such as in a chemical reaction taking place and in problems concerned with dissociating fluids. The volumetric rate of heat generation has been assumed to be constant or a function of space variables whilst some other studies have considered directly the frictional heating and the expansion effect. Foraboschi and Federico [26] assumed volumetric rate of heat generation of the type $Q=Q_{0}\left(T-T_{0}\right)$ when $T \geq T_{0}$, and $Q=0$ when $T<T_{0}$ in their study of the steady state temperature profiles for linear, parabolic and piston-flow in circular pipes, The relations above, as explained by Foraboschi and Federico, are valid as an approximation of the state of some exothermic process increasing in temperature and having $T_{0}$ as the onset temperature. When the inlet temperatures are not less than $T_{0}$, they used $Q=Q_{0}\left(T-T_{0}\right)$ and studied its effect on the heat transfer in laminar flow of non-Newtonian heat-generating fluids. Moalem [27] studied the effect of temperaturedependent heat sources of the form $Q_{0} \square(a+b T)^{-1}$, such as the one occurring in electrical heating, on the steady-state heat transfer within a porous medium.

Hence in this paper we investigate the effects of non-uniform heat source as in Eq. (4), (which can bring out the effects of exothermic process and the effects of electrical heating) and the variable wall temperature on the heat transfer characteristics of a viscous fluid over a nonlinearly stretching sheet.

\section{Mathematical formulation of the problem}

Consider the two dimensional flow of an incompressible viscous fluid over a stretching surface. The $x$-axis is taken along the stretching surface in the direction of the motion and the $y$-axis is perpendicular to it; see for details [21] and Fig. 1(a,b). It may be noted that 
the Navier-Stokes equations are elliptic, but when we use the boundary layer approximation they become parabolic. Hence, under the usual boundary layer approximations, the flow and heat transfer problems with non-uniform heat sources are governed by the following equations:

$\frac{\partial u}{\partial x}+\frac{\partial v}{\partial y}=0$,

$u \frac{\partial u}{\partial x}+v \frac{\partial u}{\partial y}=v \frac{\partial^{2} u}{\partial y^{2}}$

$\rho c_{p}\left(u \frac{\partial T}{\partial x}+v \frac{\partial T}{\partial y}\right)=k \frac{\partial^{2} T}{\partial y^{2}}+q^{\prime \prime \prime}$,

where $x$ and $y$ denote the cartesian coordinates along and normal to the sheet, respectively, $u$ and $v$ are the velocity components of the fluid in the $x$ and $y$ directions, respectively, $\rho$ is the fluid density, $v=(\mu / \rho)$ is the kinematic viscosity, $\mu$ is the viscosity, $T$ is the temperature, $k$ is the thermal conductivity, and $c_{p}$ is the specific heat at constant pressure. $q^{\prime \prime \prime}$ is the non-uniform heat source, which is modeled as:

$q^{\prime \prime \prime}=\left(\frac{k u_{w}(x)}{x v}\right)\left[A^{*}\left(T_{w}-T_{\infty}\right) \exp \left(-y \sqrt{\frac{b(n+1)}{2 v}} x^{\frac{n-1}{2}}\right)+B^{*}\left(T-T_{\infty}\right)\right]$,

where $A^{*}$ and $B^{*}$ are parameters of the space and temperature dependent internal heat generation/absorption. The case $A^{*}>0$ and $B^{*}>0$ corresponds to internal heat generation while $A^{*}<0$ and $B^{*}<0$ corresponds to the internal heat absorption.

The boundary sheet is stretched nonlinearly with a velocity proportional to $x$ coordinate (i.e., the distance from a slit); hence the appropriate boundary conditions for the problem are

$\left.\begin{array}{ll}u_{w}(x)=b x^{n}, v=0, T=A x^{\lambda}, & \text { at } y=0 \\ u \rightarrow 0, T \rightarrow T_{\infty} & \text { as } y \rightarrow \infty\end{array}\right\}$,

where $b$ and $n$ are parameters related to the surface stretching velocity. Introducing new similarity variables 
$\left.\begin{array}{l}u=b x^{n} f_{\eta}(\eta), \quad v=-\sqrt{\frac{b v(n+1)}{2}} x^{\frac{n-1}{2}}\left[f(\eta)+\frac{n-1}{n+1} \eta f_{\eta}(\eta)\right] \\ \text { and } \quad \eta=y \sqrt{\frac{b(n+1)}{2 v}} x^{\frac{n-1}{2}} \sqrt{ }\end{array}\right\}$,

and upon substitution of these similarity transformations into Eqs. (1), (2) and the conditions in (5), we get

$$
f_{\eta \eta \eta}=\left(\frac{2 n}{n+1}\right) f_{\eta}^{2}-f f_{\eta \eta}
$$

with the boundary conditions

$$
\begin{aligned}
& f_{\eta}(\eta)=1, \quad f(\eta)=0 \\
& f_{\eta}(\eta) \rightarrow 0 \text {, } \\
& \left.\begin{array}{ll}
\text { at } & \eta=0 \\
\text { as } & \eta \rightarrow \infty
\end{array}\right\} \text {. }
\end{aligned}
$$

Similarly upon substitution of similarity variables in Eq. (6) into Eq. (3) we obtain

$\theta_{\eta \eta}+\operatorname{Pr} f \theta_{\eta}+\left(\frac{2}{n+1}\right)\left\{B^{*}-\lambda \operatorname{Pr} f_{\eta}\right\} \theta+\left(\frac{2}{n+1}\right) A^{*} f_{\eta}=0$

where $T-T_{\infty}=\left(T_{w}-T_{\infty}\right) \theta(\eta)$ and the boundary conditions in Eq. (5) take the form

$$
\left.\begin{array}{lll}
\theta(\eta)=1 \quad \text { at } & \eta=0 \\
\theta(\eta) \rightarrow 0 & \text { as } & \eta \rightarrow \infty
\end{array}\right\}
$$

The shear stress at the wall is given by

$$
\tau_{w}=\mu\left(\frac{\partial u}{\partial y}\right)_{y=0}=b \mu \sqrt{\frac{b(n+1)}{2 v}} x^{\frac{3 n-1}{2}} f_{\eta \eta}(0) .
$$

The local wall heat flux is defined as

$$
q_{w}=-k\left(\frac{\partial T}{\partial y}\right)_{y=0}=-k\left(T_{w}-T_{\infty}\right) \sqrt{\frac{b(n+1)}{2 v}} x^{\frac{n-1}{2}} \theta_{\eta}(0) .
$$

Since there is no exact solution for the nonlinearly stretching boundary value problem, we opt for an efficient shooting technique with a fourth-order Runge-Kutta scheme.

\section{Numerical solution}

Analytical solution for the flow problem with $n \neq 1$ does not exist so consequently, one has to use a numerical technique. The nonlinear differential Eqs. (7) and (9) with boundary conditions (8) and (10) are solved numerically by the shooting technique with a 
fourth-order Runge-Kutta method [28,29]. The nonlinear differential equations are first decomposed into to a system of first order differential equations

$$
\left.\begin{array}{l}
\frac{d f_{0}}{d \eta}=f_{1}, \\
\frac{d f_{1}}{d \eta}=f_{2}, \\
\frac{d f_{2}}{d \eta}=\left(\frac{2 n}{n+1}\right)\left(f_{1}\right)^{2}-f_{0} f_{2} \\
\frac{d \theta_{0}}{d \eta}=\theta_{1}, \\
\frac{d \theta_{1}}{d \eta}=\left(\frac{2}{n+1}\right)\left\{\lambda \operatorname{Pr} f_{1}-B^{*}\right\} \theta_{0}-\operatorname{Pr} f \theta_{1}-A^{*} f_{1}
\end{array}\right\}
$$

with the boundary conditions

$$
\left.\begin{array}{lll}
f_{1}(0)=1, & f_{0}(0)=0, & \theta_{0}(0)=1 \\
f_{2}(\infty)=0, & \theta_{0}(\infty)=0 &
\end{array}\right\},
$$

where $f_{0}(\eta)=f(\eta)$ and $\theta_{0}(\eta)=\theta(\eta)$. The boundary value problem above is first converted into an initial value problem (IVP) by appropriately guessing the missing slopes $f_{2}(0)$ and $\theta_{1}(0)$. Then the resulting IVP is solved by the shooting method for several sets of values of the parameters. The step size of $h=0.01$ is employed for the computational purposes and the error tolerance of $10^{-6}$ is being used.

\section{Analytical solution (a special case)}

In this special case, we investigate the solution of Eqs. (7) and (9) with the boundary conditions (8) and (10), when $n=1$ and $\lambda=2$ as follows:

\subsection{Solution of the momentum equation}

Substituting $n=1$ into Eq. (7), we obtain the momentum boundary layer equation as:

$$
f_{\eta \eta \eta}=f_{\eta}^{2}-f f_{\eta \eta},
$$

with the conditions

$$
\begin{aligned}
& f_{\eta}(\eta)=1, \quad f(\eta)=0 \\
& f_{\eta}(\eta) \rightarrow 0 \text {, } \\
& \left.\begin{array}{ll}
\text { at } & \eta=0 \\
\text { as } & \eta \rightarrow \infty
\end{array}\right\} \text {. }
\end{aligned}
$$


The momentum boundary layer Eq. (15) with conditions (16) has the exact solution (for details see Vajravelu [21])

$$
f(\eta)=1-\exp (-\eta)
$$

\subsection{Solution of thermal boundary layer equation}

Similarly, when $n=1$ and $\lambda=2$, the governing thermal boundary layer Eq. (9) reduces to

$\theta_{\eta \eta}+\operatorname{Pr} f \theta_{\eta}+\left\{B^{*}-2 \operatorname{Pr} f_{\eta}\right\} \theta+A^{*} f_{\eta}=0$

with conditions

$$
\left.\begin{array}{lll}
\theta(\eta)=1 & \text { at } & \eta=0 \\
\theta(\eta) \rightarrow 0 & \text { as } & \eta \rightarrow \infty
\end{array}\right\} .
$$

Analytical solution for the differential equation (18) subject to the conditions (19) can be obtained in terms of Kummer's function as:

$$
\left.\begin{array}{l}
\theta(\eta)=c_{1}\left(e^{-\eta}\right)^{\frac{a_{0}+b_{0}}{2}} M\left(\frac{a_{0}+b_{0}}{2}-2,1+b_{0},-\operatorname{Pr} e^{-\eta}\right)+c_{2} e^{-\eta}, \\
\text { where } \quad a_{0}=\operatorname{Pr}, \quad b_{0}=\sqrt{a_{0}^{2}-4 B^{*}}, c_{2}=\frac{-A^{*}}{\left(4-2 \operatorname{Pr}+B^{*}\right)}
\end{array}\right\} .
$$

\section{Results and discussion}

Heat transfer characteristics of the viscous boundary layer flow over a nonlinearly stretching sheet with non-uniform heat source are investigated. The shooting technique with a fourth-order Runge-Kutta scheme is employed to obtain the solution for the oneway coupled nonlinear boundary value problem. Also, as a special case, we obtained an analytical solution (when $n=1$ and $\lambda=2$ ) to the case of Newtonian fluid. The results for the Newtonian case are used to validate the numerical results for the general case $n \neq 1$. The parameters involved in the study are $n$ (the power law-index), $\lambda$ (the temperature parameter), $\operatorname{Pr}$ (the Prandtl number), and $A^{*}$ (the space dependent heat source/sink) and $B^{*}$ (the temperature dependent heat source/sink). Since Vajravelu [21], Cortell $[23,24]$ already studied the effects of the parameters $n$ and Pr on the flow and heat 
transfer characteristics. Therefore, we focus our attention on the other parameters $\lambda$, $A^{*}$ and $B^{*}$.

The effects of the physical parameters involved in the heat transfer analysis are depicted in Figs. 2 through 6. The influence of the power-law index $n$ is depicted in Fig. 2. From this figure it is clear that as the nonlinear stretching parameter $n$ increases, an increase in temperature occurs. The effect of the parameter $\lambda$ on heat transfer is typical as in Grubka and Bobba [6], which is presented in Fig. 3. From this figure it can be seen that, the magnitude of the parameter $\lambda$ dictates the direction of heat transfer. From this figure we can also see that, the increasing effect of $\lambda$ is to decrease the magnitude of temperature in the boundary layer, and hence there is heat transfer from sheet to liquid. Fig. 4 shows the effect of the Prandtl number on the heat transfer. Increasing the Prandtl number (Pr) will decrease the temperature. That is, an increase in the Prandtl number is to decrease the thickness of the thermal boundary layer. Also this phenomenon is true with $\lambda$. However, quite opposite is true with the other parameters.

Figs. 5 and 6 show the effects of the heat source/sink parameter on the temperature. The heat generation/absorption clearly affects the flow and temperature of the fluid. It is the cumulative influence of the flow and temperature-dependent heat source/sink parameter that determines the extent to which temperature falls or rises in the boundary layer region. From the plots it is clear that, the energy is released for increasing values of $A^{*}>0, B^{*}>0$ and this causes the magnitude of temperature to increase, where as energy is absorbed for decreasing values of $A^{*}<0, B^{*}<0$. Non-uniform heat sinks corresponding to $A^{*}<0, B^{*}<0$ can contribute to quenching the heat from stretching sheet effectively.

The numerical results for the wall temperature gradient $\theta^{\prime}(0)$ are documented in Table 1. These results reveal that the effect of increasing values of $A^{*}$ and $B^{*}$ is to increase the wall temperature gradient $\theta^{\prime}(0)$, but quite opposite is the phenomenon with the parameters Pr and $\lambda$. 
Acknowledgments The authors are thankful to the reviewers for their insightful reviews, invaluable comments and suggestions, which have helped improvement of this article. Dr. Mahantesh M. Nandeppanavar would like to thank University Grants Commission, New-Delhi, India for supporting this work under Major Research Project [Grant No. 3959/2010(SR)]. Dr. Chiu-On Ng would like to thank the support by the Research Grants Council of the Hong Kong Special Administrative Region, China, through Project No. HKU 715510E.

\section{References}

[1] B.C. Sakiadis, Boundary layer behavior on continuous solid surfaces: I Boundary layer equations for two dimensional and axisymmetric flows, AIChE. J. 7 (1961) 26-28.

[2] B.C. Sakiadis, Boundary layer behavior on continuous solid surfaces: II Boundary layer on a continuous flat surface, AIChE. J. 7 (1961) 221-225.

[3] L.E. Erickson, L.T. Fan, V.G. Fox, Heat transfer on a moving continuous flat plate with suction or injection, Ind. Eng. Chem. Fund. 5 (1966) 19-25.

[4] L.J. Crane, Flow past a stretching sheet, ZAMP 21 (1970) 645-647.

[5] A.K. Singh, Heat source and radiation effects on magneto convection flow of a viscoelastic fluid past a stretching sheet: analysis with Kummer's function, Int. Comm. Heat Mass Transfer 35 (2008) 637-642.

[6] L.J. Grubka, K.M. Bobba, Heat transfer characteristics of a continuous stretching surface with variable temperature, ASME J. Heat Transfer 107 (1985) 248-250.

[7] M.S. Abel, M.M. Nandeppanavar, Effects of thermal radiation and non-uniform heat source on MHD flow of viscoelastic fluid flow and heat transfer over a stretching sheet, Int. J. Appl. Mech. Eng. 21 (2007) 903-918.

[8] M.S. Abel, M.M. Nandeppanavar, Heat transfer in a MHD viscoelastic boundary layer flow over a stretching sheet with non-uniform heat source/sink, Comm. Nonlinear Sci. Num. Sim. 14 (2009) 2120-2131.

[9] M.S. Abel, M.M. Nandeppanavar, Heat transfer in a MHD viscoelastic boundary layer flow over a stretching sheet with space and temperature dependent heat source, Int. J. Appl. Mech. Eng. 13 (2008) 293-309. 
[10] M.S. Abel, P.G. Siddheshwar, M.M. Nandeppanavar, Heat transfer in viscoelastic boundary layer flow over a stretching sheet with viscous dissipation and nonuniform heat source, Int. J. Heat Mass Transfer 50 (2007) 960-966.

[11] M.S. Abel, N. Mahesha, Heat transfer in MHD fluid flow over a stretching sheet with variable thermal conductivity, non-uniform heat source and radiation, Appl. Math. Model. 32 (2008) 1965-1983.

[12] M.E. Ali, On thermal boundary layer on a power law stretched surface with suction and injection, Int. J. Heat and Fluid Flow 16 (1995) 280-290.

[13] R. Tsai, K.H. Huang, J.S. Huang, Flow and heat transfer over an unsteady stretching surface with non-uniform heat source, Int. Comm. Heat Mass Transfer 35 (2008) 1340-1343.

[14] V. Kumaran, G. Ramanaih, A note on the flow over stretching sheet, Arch. Mech. 116 (1996) 229-233.

[15] E. Magyari, B. Keller, Heat mass transfer in the boundary layers on an exponentially stretching sheet, J. Phys. D: Appl. Phys. 32 (1999) 577-585.

[16] E.M.A Elbashbeshy, Heat transfer over an exponentially stretching continuous surface with suction, Arch. Mech. 53 (2001) 643-651.

[17] S.K. Khan, E. Sanjayanand, Viscoelastic boundary layer flow and heat transfer over an exponential stretching sheet, Int. J. Heat Mass Transfer 48 (2005) 15341542.

[18] E. Sanjayanand, S.K. Khan, On heat and mass transfer in viscoelastic boundary layer flow over an exponentially stretching sheet, Int. J. Therm. Sci. 45 (2006) 819-828.

[19] M. Sajid, T. Hayat, Influence of thermal radiation on the boundary layer flow due to an exponentially stretching sheet, Int. Comm. Heat Mass Transfer 35 (2008) 347-356.

[20] M.K. Partha, P.V.S.N. Murthy, G.P. Rajasekhar, Effect of viscous dissipation on the mixed convection of heat transfer from an exponential stretching surface, Heat Mass Transfer 41 (2005) 360-366.

[21] K. Vajravelu, Viscous flow over a nonlinearly stretching sheet, Appl. Math. Comput. 124 (2001) 281-288. 
[22] K. Vajravelu, J.R. Cannon, Fluid flow over a nonlinearly stretching sheet, Appl. Math. Comput. 181 (2006) 609-618.

[23] R. Cortell, Viscous flow and heat transfer over a nonlinearly stretching sheet, Appl. Math. Comput. 184 (2007) 864-873.

[24] R. Cortell, Effects of Viscous Dissipation and radiation on the thermal boundary layer over a non-linearly stretching sheet, Phys. Lett. A 372 (2008) 631-636.

[25] R. Cortell, Similarity solutions for the flow and heat transfer of a quiescent fluid over a nonlinearly stretching sheet, J. Mater. Process Technol. 203 (2008) 176183.

[26] F.P. Foraboschi, I.D. Federico, Heat transfer in laminar flow of non-Newtonian heat-generating fluids, Int. J. Heat Mass Transfer 7 (1964) 315-318.

[27] D. Moalem, Steady state heat transfer within porous medium with temperature dependent heat generation, Int. J. Heat Mass Transfer 19 (1976) 529-537.

[28] T. Cebeci, P. Bradshaw, Physical Computational Aspects of Convective Heat Transfer, Springer-Verlag, New-York, 1984.

[29] S.D. Conte, C.de. Boor, Elementary Numerical Analysis, McGraw-Hill, New York, 1972. 


\section{Nomenclature}

$\begin{array}{ll}b & \text { stretching rate } \\ x & \text { horizontal coordinate } \\ y & \text { vertical coordinate } \\ u & \text { horizontal velocity component } \\ v & \text { vertical velocity component } \\ T & \text { temperature } \\ t & \text { time } \\ c_{p} & \text { specific heat } \\ f & \text { dimensionless stream function } \\ \text { Pr } & \text { Prandtl number } \\ A^{*} & \text { space dependent heat source/sink } \\ B^{*} & \text { temperature dependent heat source/sink } \\ n & \text { power-law index }\end{array}$

\section{Greek symbols}

$\eta \quad$ similarity variable

$\theta$ dimensionless temperature

$k$ thermal conductivity

$\mu \quad$ viscosity

$v \quad$ kinematic viscosity

$\rho$ density

$\tau_{w} \quad$ shear stress

$\lambda$ temperature parameter

\section{Subscripts}

$\eta \quad$ first derivative w. r. t. $\eta$

$\eta \eta \quad$ second derivative w. r. t. $\eta$

$\eta \eta \eta \quad$ third derivative w. r. t. $\eta$ 
Table1. Values of the Nusselt number $\theta^{\prime}(0)$ for several sets of values of the parameters.

\begin{tabular}{|c|c|c|c|c|}
\hline \multirow[t]{2}{*}{ Parameters } & \multirow[t]{2}{*}{ Values } & \multicolumn{3}{|c|}{$-\theta^{\prime}(0)$} \\
\hline & & $n=0.5$ & $n=1.0$ & $n=1.5$ \\
\hline \multirow{3}{*}{$\lambda$} & 1.0 & 0.994706 & 0.864169 & 0.784960 \\
\hline & 2.0 & 1.452543 & 1.237484 & 1.100034 \\
\hline & 3.0 & 1.818398 & 1.544861 & 1.365733 \\
\hline \multirow{3}{*}{$\operatorname{Pr}$} & 1.0 & 1.452443 & 1.237484 & 1.00034 \\
\hline & 2.0 & 2.226426 & 1.927176 & 1.732455 \\
\hline & 3.0 & 2.799134 & 2.436357 & 2.199036 \\
\hline \multirow{3}{*}{$A^{*}$} & -0.1 & 1.561825 & 1.354497 & 1.22213 \\
\hline & 0.0 & 1.507134 & 1.295990 & 1.161123 \\
\hline & 0.1 & 1.452443 & 1.237484 & 1.00034 \\
\hline \multirow{3}{*}{$B^{*}$} & -0.1 & 1.560166 & 1.334991 & 1.188739 \\
\hline & 0.0 & 1.508454 & 1.288311 & 1.146251 \\
\hline & 0.1 & 1.452443 & 1.237484 & 1.100034 \\
\hline
\end{tabular}

(Note: While studying the effect of individual parameters the following values are used $\left.\lambda=2.0, \operatorname{Pr}=1.0, A^{*}=0.1, B^{*}=0.1\right)$. 


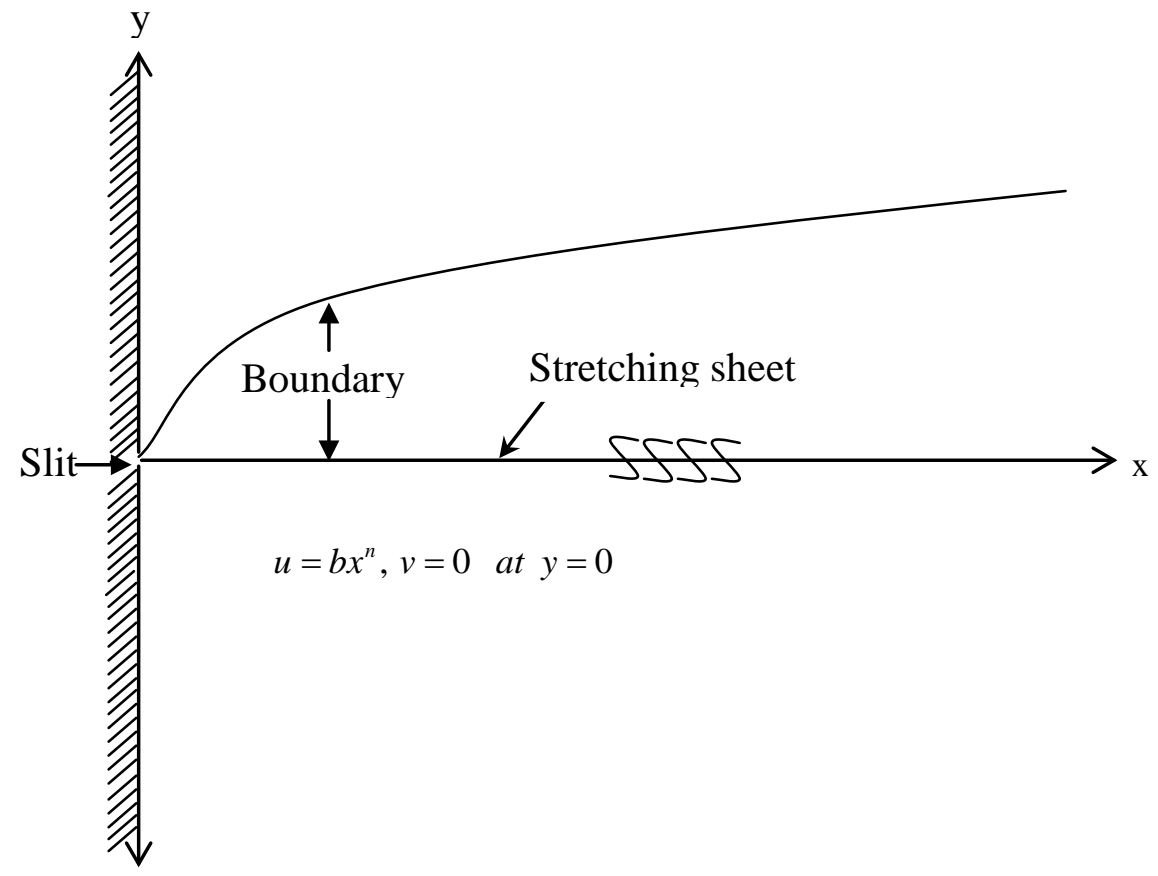

Fig. 1(a): Schematic diagram of the stretching sheet

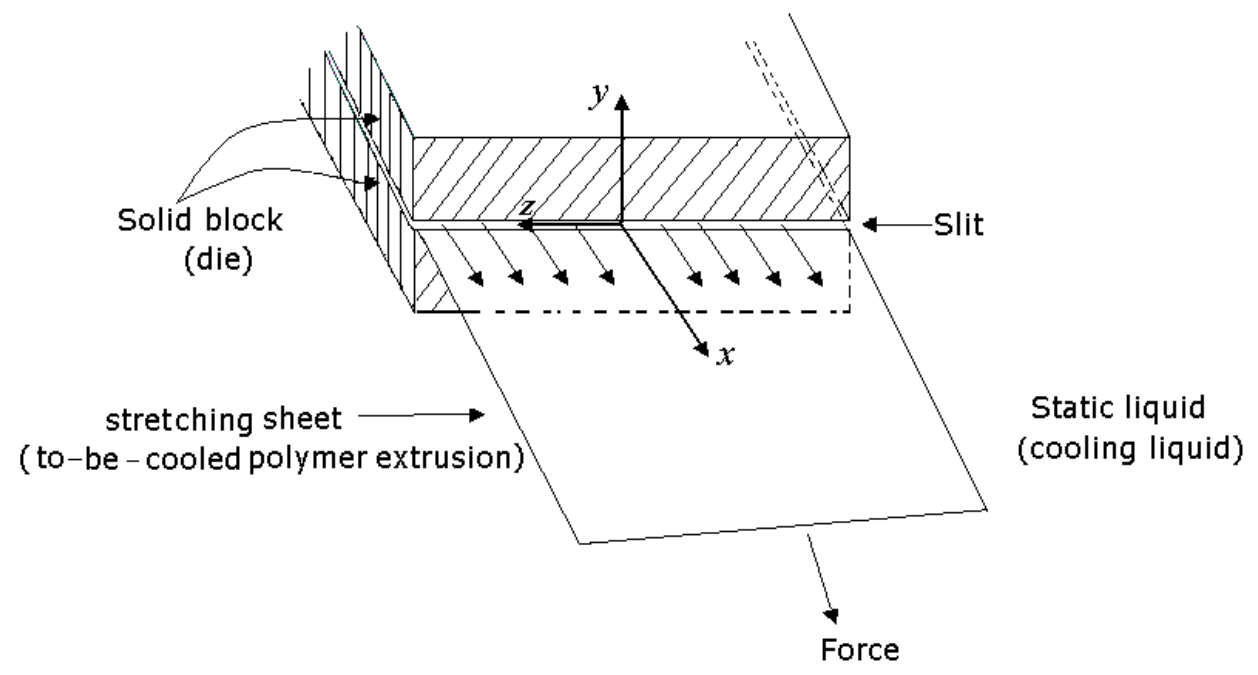

Fig. 1(b): Schematic of a polymer extrusion process 


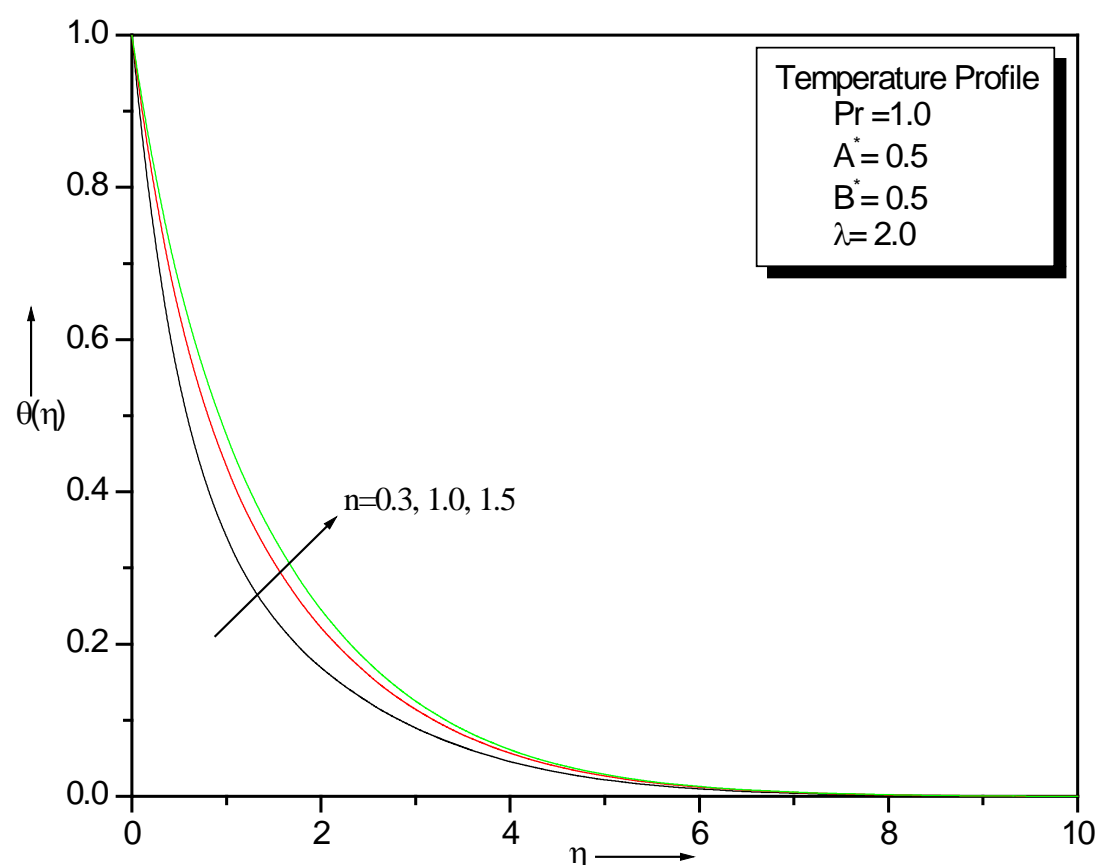

Fig 2: effect of power-law index parameter $\mathrm{n}$ on temperature profile

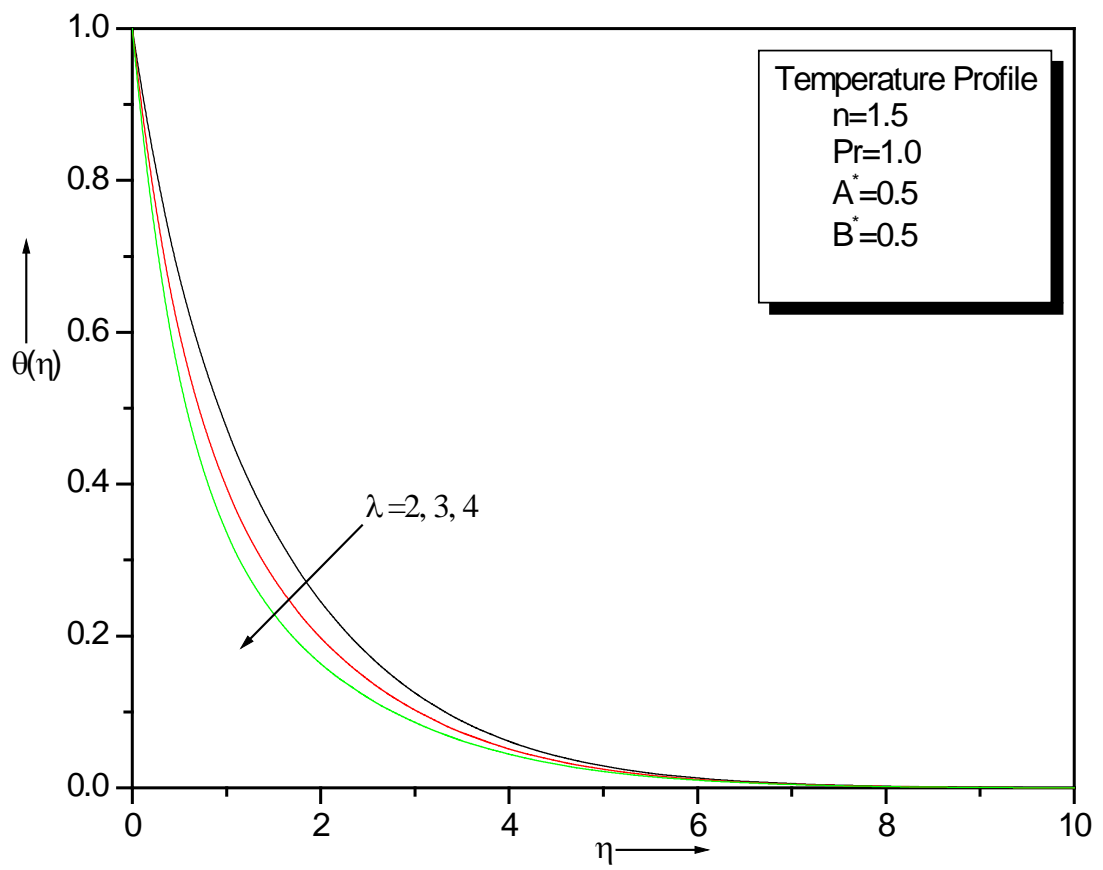

Fig 3: Effect of $\lambda$ on temperature profile 


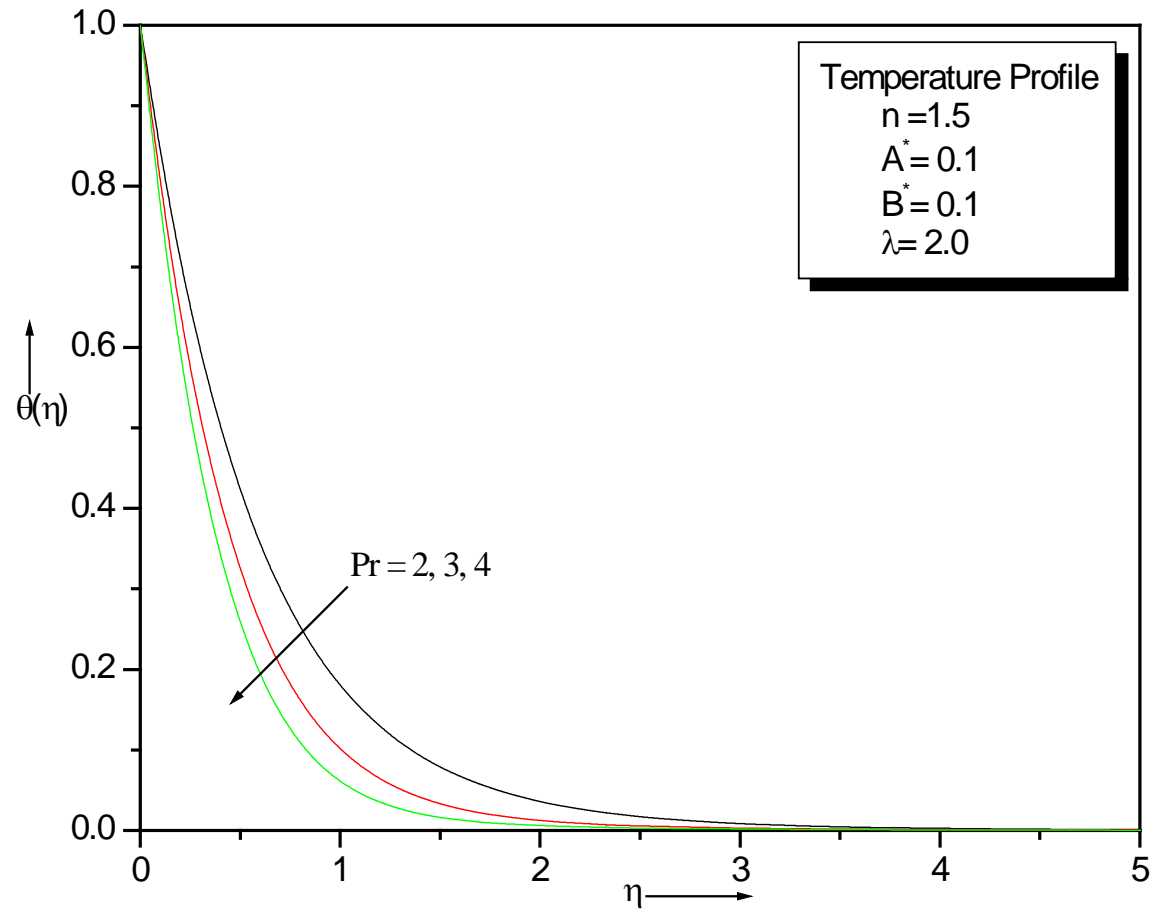

Fig 4: Effect of Pr on Temperature profile

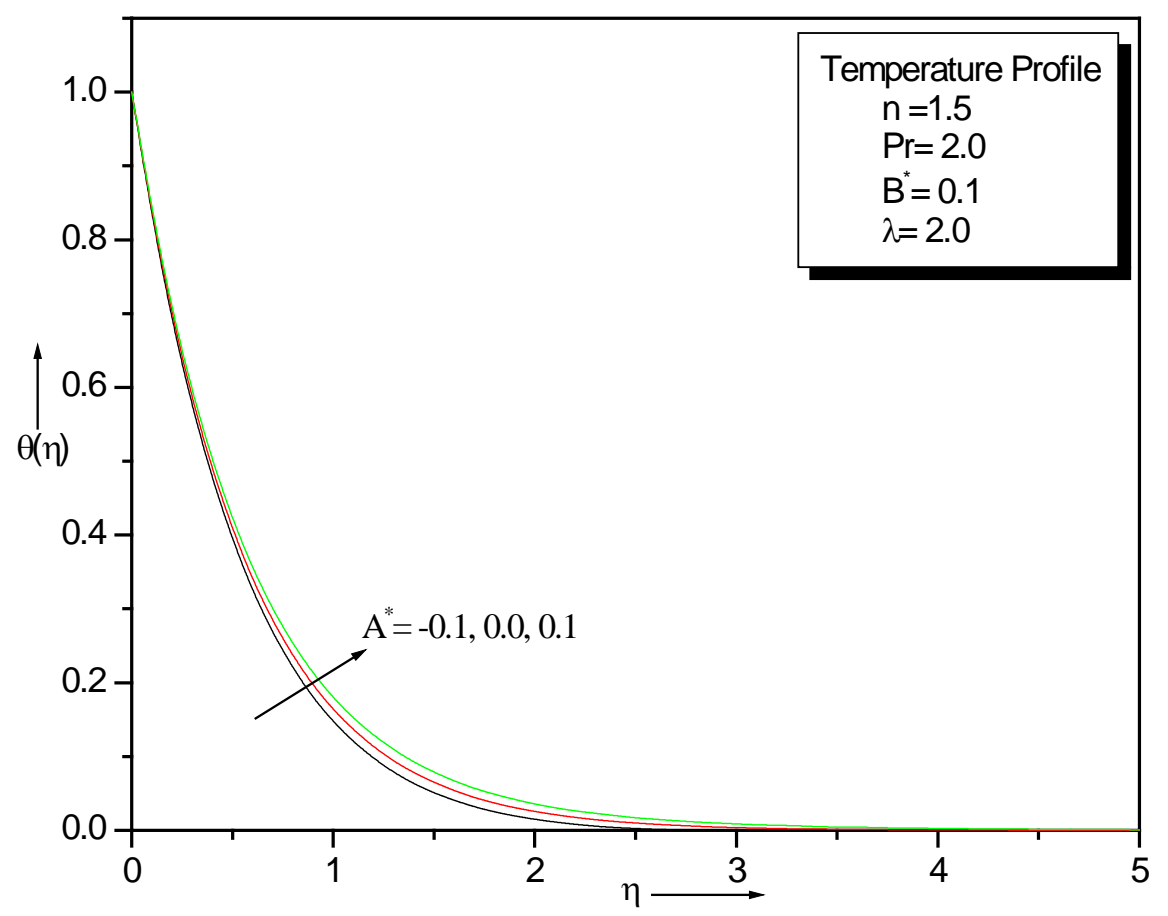

Fig 5: effect of $A^{*}$ on temperature profile 


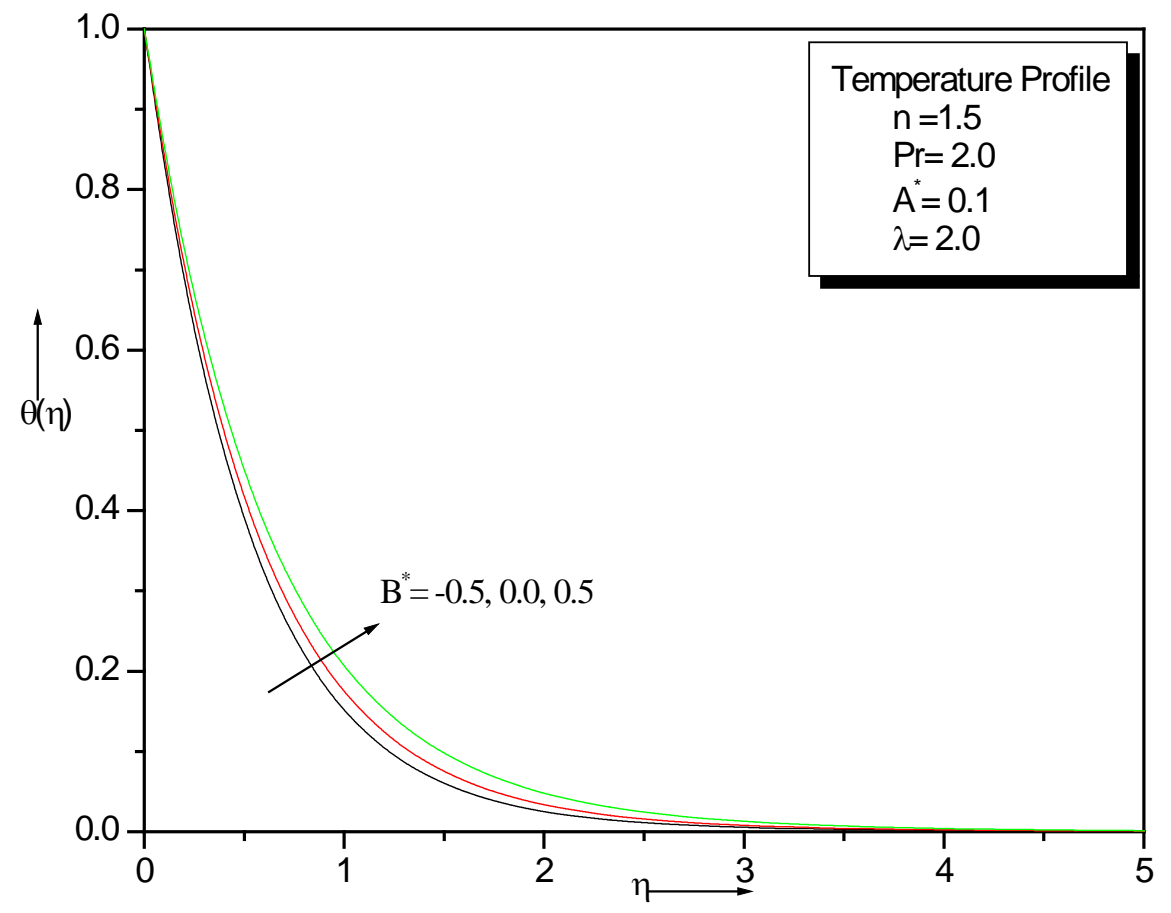

Fig 6: Effect of $\mathrm{B}^{*}$ on temperature profile 